\title{
The Effect of Number of Teeth and Chewing Ability on Cognitive Function of Elderly in UAE: A Pilot Study
}

\author{
Zahra Seraj, Dana Al-Najjar, Mohammed Akl, Noorelrahman Aladle, Yousif Altijani, \\ Ahmed Zaki, and Sausan Al Kawas
}

College of Dental Medicine, University of Sharjah, Sharjah, UAE

Correspondence should be addressed to Sausan Al Kawas; sausan@sharjah.ac.ae

Received 20 June 2017; Revised 16 September 2017; Accepted 24 September 2017; Published 14 November 2017

Academic Editor: Tommaso Lombardi

Copyright (C) 2017 Zahra Seraj et al. This is an open access article distributed under the Creative Commons Attribution License, which permits unrestricted use, distribution, and reproduction in any medium, provided the original work is properly cited.

\begin{abstract}
Cognitive decline is one of the major causes of disability among the aging population. The aim of this study was to explore the relationship between oral health parameters (number of teeth, chewing ability, and presence of a denture) and cognitive function in the elderly across the UAE. Fifty persons (age $\geq 60 ; 71.26 \pm 10.23$ ) were enrolled in the study. Cognitive status was assessed using the standardized mini-mental state examination (SMMSE) and accordingly, cognitively normal subjects scoring $\geq 24$ were considered as the control group and cognitively impaired individuals scoring $\leq 23$ were considered as the low scoring group. Chewing ability was examined, number of teeth was noted, and demographical data was collected. The results of this pilot study showed that individuals with low SMMSE scores were significantly less educated $(P<0.01)$ and had fewer number of remaining teeth $(P<0.05)$ and impaired chewing ability $(P<0.05)$. These results demonstrate a significant link between the number of teeth, chewing ability, and cognitive function. However, this pilot study had its limitations and was the first of its kind in the UAE and Gulf region; therefore, future research addressing the limitations is needed to further explore this association.
\end{abstract}

\section{Introduction}

On a global scale, according to the United Nations, by midcentury, the number of people over 60 years will represent $32 \%$ of the world population [1]. Considering the UAE, the proportion of elderly persons aged 60 years and above in the year 2000 was $5.1 \%$ and is expected to increase to $23.6 \%$ by 2025 [2]. The UAE provides a unique population in which the UAE nationals make up $11.6 \%$ of the population while the other $88.4 \%$ are expatriates [3], many of whom have been born in the UAE or have lived there for generations. Thus, it provides a controlled environment in which we can study both UAE nationals and expatriates. This, in addition to the rise in life expectancy from 74 years to 78 years [2], means there is an increased need to address age-related chronic diseases within the UAE.

Dementia, a neurocognitive disorder, is a broad term used to describe a range of symptoms associated with a decline in cognitive function and is one of the most common age-associated diseases. It is characterized by memory loss, neurological symptoms, disorientation, impaired judgement, personality changes, and loss of motor function [4]. Diagnosing dementia remains a challenge for physicians due to the symptom overlap with many other conditions such as depression, vitamin deficiencies, and thyroid dysfunction [5]. There is no cure for dementia and treatment remains to address the patients' symptoms and attempts to improve their quality of life and that of their families. Therefore, an understanding of early decline in cognitive function and the associated predisposing risk factors is becoming more important, shifting the focus towards prevention and delayed onset of disease.

Among the literature, links have been established between certain systemic factors such as diabetes [6, 7] and cardiovascular diseases [8] and their bidirectional association with poor dental and periodontal health. The links are increasingly being investigated as a possible means to address risk factors. Accordingly, the potential relationship between oral health and cognitive function has become a topic of interest. A wide range of studies have been conducted to assess the link between oral health conditions such as tooth loss [5, 9-19], impaired chewing ability [6, 20-26], and 
the absence of a denture $[27,28]$ in relation to cognitive impairment. The rationale is based upon the sensory and motor cortical remapping hypothesis, relating tooth loss and impaired masticatory ability to neuroanatomical and chemical changes that occur in the brain due to the reduction in sensory input and cortical blood flow $[25,26]$. Additionally, studies have linked dental status and the use of dentures to improved nutritional intake [27, 29-38] and have established a relationship between low dietary intake of omega- 3 fatty acids [38, 40], antioxidants [41, 42], and vitamin B12 [40-42] and an increased risk for cognitive decline [43-45]. Systemic factors such as hypertension [46-48], obesity [49, 50], and hypercholesterolemia [39] were also found to be risk factors. Periodontal disease and periodontal inflammatory blood markers have also been investigated in relation to cognitive decline [51].

To the best of our knowledge, no similar studies have been conducted within the Middle East or Gulf region. Therefore, the objectives of this pilot study are to (1) examine the relationship between the number of remaining teeth and cognitive ability, (2) examine the relationship between chewing status and cognitive ability, (3) examine the relationship between the presence of a denture and cognitive ability, and (4) test whether other demographic characteristics may be related to cognitive function.

\section{Materials and Method}

2.1. Participants. The Medical Ethics Committee of the University of Sharjah, UAE, approved data collection for this study. The sample consisted of 50 participants, 25 males and 25 females, all 60 years and above within the UAE. Written informed consent was obtained from each of the participants prior to their involvement in the study. The exclusion criteria included any disorders interfering with psychometric assessment such as severe blindness or terminal illness and/or conditions such as depression or history of cerebrovascular accident.

2.2. Assessment of Cognitive Mental Status. The Standardized Mini-Mental State Examination test (SMMSE) [52] was translated into Arabic using a forward-backward approach and was used to measure participants' global cognitive status. The SMMSE (score range $0-30$ ) is the most common instrument used as a screening tool for cognitive function. It tests orientation, registration, short-term memory, language use, comprehension, and basic motor skills. According to the examination guidelines, participants were considered part of the low scoring group at a score of 23 or below, while those scoring 24 and above represented normal cognitive function (SMMSE $\leq 23$ or SMMSE $\geq 24$, resp.).

2.3. Assessment of Oral Health Parameters. Three parameters were explored and data was collected for each participant, number of teeth present, presence/absence of denture, and chewing ability using the Index of Chewing Ability (ICA) [53] which was translated into Arabic using a forwardbackward approach. The ICA consists of five yes/no questions (score range $0-5$ ) based on the ability to chew certain foods.
TABLE 1: Demographic characteristics of the subjects.

\begin{tabular}{|c|c|c|c|c|}
\hline & $\begin{array}{c}\text { Control } \\
n=19\end{array}$ & $\begin{array}{c}\text { Low SMMSE score } \\
n=31\end{array}$ & Pearson's $r$ & $P$ value \\
\hline Age & $67.7 \pm 5.4$ & $73.5 \pm 11.8$ & -0.277 & $0.052^{*}$ \\
\hline \multicolumn{5}{|l|}{ Gender } \\
\hline Male & $11(57.9)$ & $14(45.2)$ & \multirow{2}{*}{0.124} & \multirow{2}{*}{$0.382^{\dagger}$} \\
\hline Female & $8(42.1)$ & $17(54.8)$ & & \\
\hline \multicolumn{5}{|l|}{ Nationality } \\
\hline UAE & $4(16.0)$ & $21(84.0)$ & \multirow{2}{*}{-0.453} & \multirow{2}{*}{$0.001^{\dagger}$} \\
\hline Expatriate & $15(60.0)$ & $10(40.0)$ & & \\
\hline \multicolumn{5}{|l|}{ Education } \\
\hline Uneducated & $3(10.3)$ & $24(16.7)$ & \multirow{2}{*}{0.600} & \multirow{2}{*}{$0.001^{\dagger}$} \\
\hline Educated & $16(8.7)$ & $17(14.3)$ & & \\
\hline \multicolumn{5}{|l|}{ Health } \\
\hline Hypertension & $7(30.4)$ & $16(69.6)$ & -0.144 & $0.387^{\dagger}$ \\
\hline Diabetes & $7(29.2)$ & $17(70.8)$ & -0.175 & $0.255^{\dagger}$ \\
\hline \multicolumn{5}{|l|}{ Smoking } \\
\hline Nonsmoker & $4(21.1)$ & $15(16.0)$ & \multirow{2}{*}{0.108} & \multirow{2}{*}{$0.459^{\dagger}$} \\
\hline Smoker & $4(5.0)$ & $27(26.0)$ & & \\
\hline
\end{tabular}

SMMSE: Standardized mini-mental state examination; ${ }^{\dagger}$ Chi Square, as no., $\%$; ${ }^{*}$ Unpaired $T$-Test, as mean, standard deviation.

Accordingly, those scoring less than 5 were considered to have impaired chewing ability while a score of 5 indicated competent chewing ability (ICA $\leq 4$ or ICA $=5$, resp.).

2.4. Other Recorded Variables. Questionnaires were administered through interviews to collect the data. Demographic variables (age, gender, and education level), lifestyle variables (smoking status), and the presence of chronic medical diseases such as cancer, cerebrovascular disease, myocardial infarction, diabetes mellitus, and hypertension were noted.

2.5. Statistical Analysis. Statistical analyses were performed using SPSS ${ }^{\circledR}$ Ver. 24.0 for Mac OS X. Clinical variables were analysed using independent $t$-tests and the chi-square test. The Pearson correlation was conducted to analyse correlations between cognitive impairment, dental health status, chewing ability, and denture presence. Two-tailed $P$ values were calculated in all the analyses. Differences were considered statistically significant at $P<0.05$.

\section{Results}

The subjects were divided into two groups according to their SMMSE scores (low scoring, SMMSE $\leq 23, n=31$ or $\mathrm{SMMSE} \geq 24, n=19$; control). Table 1 shows the demographic characteristics of the subjects included in the study and the summary statistics of oral health variables and SMMSE scores are listed in Table 2. The subjects with low SMMSE scores were found to be significantly less educated, had fewer remaining teeth, and, according to the ICA, had impaired chewing ability. It was also noted among nationals. No other differences were observed in all the other characteristics. 
TABLE 2: Summary statistics of oral health variables and SMMSE scores.

\begin{tabular}{lccc}
\hline & Control & Low SMMSE score & Pearson's $r$ \\
\hline Teeth remaining & $n=19$ & $19(86.4)$ & \\
$(0-10)$ & $3(13.6)$ & $6(54.5)$ & 0.465 \\
$(11-21)$ & $5(45.5)$ & $6(35.3)$ & $0.04^{\dagger}$ \\
$(22-32)$ & $11(64.7)$ & $11(45.8)$ & 0.320 \\
Chewing ability & $13(52.4)$ & $20(76.9)$ & $0.04^{\dagger}$ \\
Competent & $6(23.1)$ & $5(71.4)$ & 0.078 \\
Impaired & $2(28.6)$ & $26(60.5)$ & $0.695^{\dagger}$ \\
Denture & $17(39.5)$ & & \\
Present & & & \\
Absent & &
\end{tabular}

SMMSE: Standardized mini-mental state examination; ${ }^{\dagger}$ Chi Square, as no., $\%$.

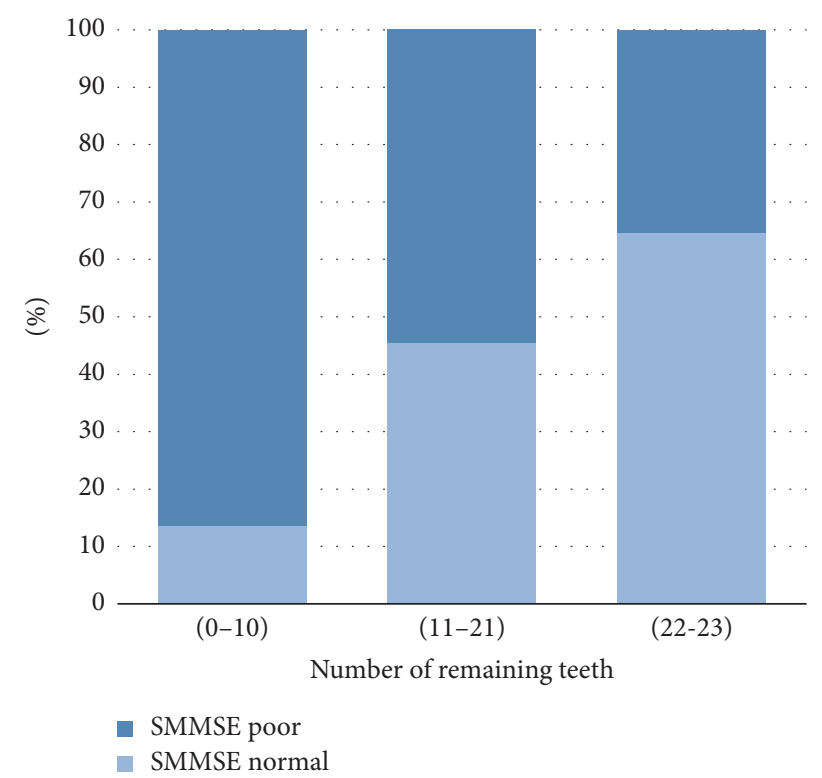

FIgure 1: Prevalence of normal SMMSE or low SMMSE score according to the number of remaining teeth.

Figure 1 shows the prevalence of a normal or low SMMSE score and the number of teeth remaining. The number of remaining teeth (range: $0-32$ ) was categorized into 3 $(22-32,11-21$, and $0-10)$. The number of remaining teeth was significantly associated with low SMMSE scores $(r=+0.465$, $P<0.05)$. The prevalence of low SMMSE score was $86.4 \%$ in subjects with $0-10$ remaining teeth, $54.5 \%$ in those with $11-21$ teeth remaining, and $35.3 \%$ in those with $22-32$ remaining teeth.

Figure 2 shows the prevalence of a normal or low SMMSE score and chewing ability. Individuals' chewing ability was classified as either competent or impaired. A significant association was observed between chewing ability and the prevalence of low SMMSE scores $(r=0.320, P<0.05)$. The prevalence of low SMMSE score was $45.8 \%$ in persons with competent chewing ability and $76.9 \%$ in those with impaired chewing ability.

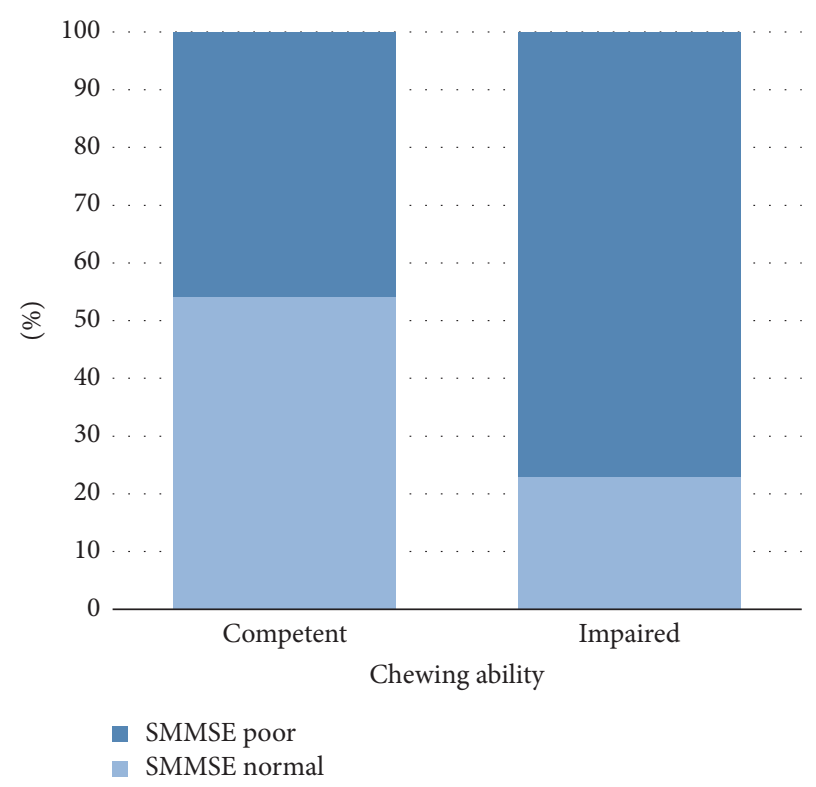

FIgURE 2: Prevalence of normal SMMSE or low SMMSE score according to chewing ability.

\section{Discussion}

This cross-sectional pilot study was designed to explore the relationship between number of remaining teeth, chewing ability, denture presence, and cognitive function in an elderly UAE population.

The study revealed that the prevalence of a low SMMSE score or poor cognition was significantly greater in association with fewer teeth remaining $(P<0.05)$ (Figure 1). These results were consistent with the literature supporting the association between tooth loss and decreased cognitive function [5, 9-19]. According to Stewart and Hirani (2007) the localized inflammatory reaction associated with periodontal disease could lead to a state of chronic low-grade systemic infection and an increase in the cytokines reaching the brain [16]. Moreover, it has been noted that individuals with fewer teeth are at a greater risk of developing nutritional 
deficiencies, especially B vitamins, which play a major role in the pathogenesis of dementia and cognitive decline [5, 40-42]. According to animal models studies, loss of teeth was associated with neuroanatomical and chemical changes that may eventually have a negative effect on learning and memory $[18,19]$. It is important to consider the likelihood of a reversed casualty, whereby individuals with poor cognition may have a lower ability to exact oral hygiene measures, such as tooth brushing and denture care, which ultimately leads to poor oral health $[54,55]$.

Additionally, a greater prevalence of low SMMSE scores was observed in persons with impaired chewing ability $(P<0.05)$ (Figure 2$)$. With the use of functional magnetic resonance imaging (fMRI) and positron emission tomography (PET), multiple studies have observed an increase in cortical blood flow [20-26] and a rise in oxygen level in the prefrontal cortex and hippocampus $[6,9]$ during mastication. Chewing has also been noted to stimulate increased cardiac activity, suggesting greater sympathetic stimulation, which increases blood glucose levels and arousal when undertaking a cognitive task $[25,26]$. Furthermore, according to Teixeira et al. there was an increased performance in relation to memory retrieval when elderly people aged 60-70 years used chewing gum [26]. In conjunction with the former, animal model studies revealed a causal relationship; occlusal hypofunction caused degenerative changes in periodontal mechanoreceptors, which in effect lead to the suppression of sensory stimulation from the periodontal ligaments during mastication and poor performance in memory and learning tests [56-59].

Although a lower number of remaining teeth and decreased chewing ability were significantly correlated with lower SMMSE scores, it must be noted that individuals from the elderly population usually present with other risk factors which may have affected their cognitive function. Hence, the decreased number of remaining teeth and impaired chewing ability may not alone lead to cognitive decline but may be markers of comorbidities [60,61].

In this pilot study, no significant relationship was found between denture presence and cognitive function $(P>0.05)$, which may be justified by the insignificant number of denture wearing individuals within the study sample.

A significant difference in SMMSE scores was noted between nationals and expatriates $(P>0.05)$, which may be related to the nationals' difficulty in accessing schools until the late 1950's [62].

Education was significantly correlated with higher SMMSE scores $(P<0.05)$. These results are in accordance with the cognitive reserve hypothesis, which assumes some aspects of life experiences such as education and knowledge act as markers of cognitive reserve and protect against age-associated cognitive decline in later life [6].

Limitations of the present study merit consideration. The primary limitation arises due to the nature of crosssectional study; hence a casual inference is difficult to make regarding the relationship between teeth remaining, chewing ability, denture presence, and poor cognitive function. Future studies with longitudinal designs would help investigate these associations. Additionally, cognitive function was assessed using only the SMMSE and although it is the most widely used means for examining cognitive function, the education level of an individual may influence it. Finally, due to the small sample size and since most of the participants were volunteers residing in elderly homes, the results of this pilot study may not represent the general population.

\section{Conclusion}

In conclusion, this pilot study revealed a significant finding whereby persons with fewer number of remaining teeth and impaired chewing ability demonstrated poor cognitive ability. The results draw attention to the possible role a person's oral health may play on their cognitive function. However, the interpretation of the results was hindered by the lack of longitudinal observation and the use of a single examination for cognitive function. Therefore, future research investigating the associations is required and the limitations need to be addressed.

\section{Conflicts of Interest}

The authors declare that they have no conflicts of interest.

\section{References}

[1] United Nations, "World population ageing 1950-2050," New York: United Nations, 2007.

[2] A. Alshaali and A. Al Jaziri, "Health Profile of Elderly Patients Registered in the Elderly Home Based Primary Care, Dubai, United Arab Emirates," Middle East Journal of Age and Ageing, vol. 12, no. 1, pp. 13-19, 2015.

[3] The World Factbook (n.d.), https://www.cia.gov/library/publications/resources/the-world-factbook/geos/print_ae.html.

[4] H. Chertkow, H. H. Feldman, C. Jacova, and F. Massoud, "Definitions of dementia and predementia states in Alzheimer's disease and vascular cognitive impairment: Consensus from the Canadian conference on diagnosis of dementia," Alzheimer's Research \& Therapy, vol. 5, no. 1, article no. S2, 2013.

[5] Y. Saito, N. Sugawara, N. Yasui-Furukori, I. Takahashi, S. Nakaji, and H. Kimura, "Cognitive function and number of teeth in a community-dwelling population in Japan," Annals of General Psychiatry, vol. 12, no. 1, article no. 20, 2013.

[6] S. Mummolo, E. Ortu, S. Necozione, A. Monaco, and G. Marzo, "Relationship between mastication and cognitive function in elderly in L'Aquila," International Journal of Clinical and Experimental Medicine, vol. 7, no. 4, pp. 1040-1046, 2014.

[7] I. B. Lamster, E. Lalla, W. S. Borgnakke, and G. W. Taylor, "The relationship between oral health and diabetes mellitus," The Journal of the American Dental Association, vol. 139, no. 10, pp. 19-24, 2008.

[8] A. I. Grudyanov, O. N. Tkacheva, and T. V. Avraamova, "Correlation of chronic periodontal disease and cardiovascular disease," Stomatologiya, vol. 96, no. 1, p. 4, 2017.

[9] N. Okamoto, M. Morikawa, K. Okamoto et al., "Relationship of tooth loss to mild memory impairment and cognitive impairment: findings from the fujiwara-kyo study," Behavioral and Brain Functions, vol. 6, article 77, 2010.

[10] C. A. Reyes-Ortiz, J. S. Luque, C. K. Eriksson, and L. Soto, "Self-reported tooth loss and cognitive function: Data from the 
Hispanic established populations for epidemiologic studies of the elderly (Hispanic EPESE)," Colombia Médica, vol. 44, no. 3 , pp. 139-145, 2013.

[11] P. S. Stein, M. Desrosiers, S. J. Donegan, J. F. Yepes, and R. J. Kryscio, "Tooth loss, dementia and neuropathology in the Nun Study," The Journal of the American Dental Association, vol. 138, no. 10, pp. 1314-1322, 2007.

[12] W. Sabbah and A. Sheiham, "The relationships between cognitive ability and dental status in a national sample of USA adults," Intelligence, vol. 38, no. 6, pp. 605-610, 2010.

[13] H. Park, S.-H. Suk, J.-S. Cheong et al., "Tooth loss may predict poor cognitive function in community-dwelling adults without dementia or stroke: The PRESENT project," Journal of Korean Medical Science, vol. 28, no. 10, pp. 1518-1521, 2013.

[14] G. Tsakos, R. G. Watt, P. L. Rouxel, C. De Oliveira, and P. Demakakos, "Tooth loss associated with physical and cognitive decline in older adults," Journal of the American Geriatrics Society, vol. 63, no. 1, pp. 91-99, 2015.

[15] S. Naorungroj, V. J. Schoenbach, L. Wruck et al., "Tooth loss, periodontal disease, and cognitive decline in the Atherosclerosis Risk in Communities (ARIC) study," Community Dentistry and Oral Epidemiology, vol. 43, no. 1, pp. 47-57, 2015.

[16] R. Stewart and V. Hirani, "Dental health and cognitive impairment in an english national survey population," Journal of the American Geriatrics Society, vol. 55, no. 9, pp. 1410-1414, 2007.

[17] M. Bergdahl, R. Habib, J. Bergdahl, L. Nyberg, and L.-G. Nilsson, "Natural teeth and cognitive function in humans," Scandinavian Journal of Psychology, vol. 48, no. 6, pp. 557-565, 2007.

[18] M. Onozuka, K. Watanabe, M. Fujita, M. Tomida, and S. Ozono, "Changes in the septohippocampal cholinergic system following removal of molar teeth in the aged SAMP8 mouse," Behavioural Brain Research, vol. 133, no. 2, pp. 197-204, 2002.

[19] T. Kato, T. Usami, Y. Noda, M. Hasegawa, M. Ueda, and T. Nabeshima, "The effect of the loss of molar teeth on spatial memory and acetylcholine release from the parietal cortex in aged rats," Behavioural Brain Research, vol. 83, no. 1-2, pp. 239242, 1997.

[20] T. Momose, J. Nishikawa, T. Watanabe et al., "Effect of mastication on regional cerebral blood flow in humans examined by positron-emission tomography with ${ }^{15} \mathrm{O}$-labelled water and magnetic resonance imaging," Archives of Oral Biolog, vol. 42, no. 1, pp. 57-61, 1997.

[21] Y. Ono, T. Yamamoto, K. Kubo, and M. Onozuka, "Occlusion and brain function: mastication as a prevention of cognitive dysfunction," Journal of Oral Rehabilitation, vol. 37, no. 8, pp. 624-640, 2010.

[22] M. Onozuka, M. Fujita, K. Watanabe et al., "Mapping brain region activity during chewing: a functional magnetic resonance imaging study," Journal of Dental Research, vol. 81, no. 11, pp. 743-746, 2002.

[23] M. Onozuka, Y. Hirano, A. Tachnibana, W. Kim, Y. Ono, K. Sasaguri et al., "Interactions between chewing and brain activities in humans," in Novel trends in brain science, $\mathrm{M}$. Onozuka and C. T. Yen, Eds., pp. 99-113, Springer, Tokyo, 2007.

[24] Y. Hirano, T. Obata, K. Kashikura et al., "Effects of chewing in working memory processing," Neuroscience Letters, vol. 436, no. 2, pp. 189-192, 2008.

[25] K. Kamiya, N. Narita, S. Iwaki, and S. Bencharit, "Improved Prefrontal Activity and Chewing Performance as Function of Wearing Denture in Partially Edentulous Elderly Individuals:
Functional Near-Infrared Spectroscopy Study," PLoS ONE, vol. 11, no. 6, p. e0158070, 2016.

[26] F. Teixeira, de. Melo Pereira Fernandes, L. P. Noronha et al., "Masticatory Deficiency as a Risk Factor for Cognitive Dysfunction," in Proceedings of the International Journal Of Medical Sciences, vol. 11, pp. 209-214, 2014, http://dx.doi.org/ 10.7150/ijms.6801.

[27] T. A. Marshall, J. J. Warren, J. S. Hand, X.-J. Xie, and P. J. Stumbo, "Oral health, nutrient intake and dietary quality in the very old," The Journal of the American Dental Association, vol. 133, no. 10, pp. 1369-1379, 2002.

[28] S. Listl, "Oral health conditions and cognitive functioning in middle and later adulthood," BMC Oral Health, vol. 14, no. 1, article no. 70, 2014.

[29] A. S. Papas, C. A. Palmer, M. C. Rounds, and R. M. Russell, "The effects of denture status on nutrition," Special Care in Dentistry, vol. 18, no. 1, pp. 17-25, 1998.

[30] F. A. Fontijn-Tekamp, M. A. vant Hof, A. P. Slater, and M. A. van Waas, "The state of dentition in relation to nutrition in elderly Europeans in the SENECA study of 1993," European Journal of Clinical Nutrition, pp. S117-22, 1993.

[31] B. Hutton, J. Feine, and J. Morais, "Is there an association between edentulism and nutritional state?" Journal of the Canadian Dental Association, vol. 68, no. 3, pp. 182-187, 2002.

[32] P. Y. Cousson, M. Bessadet, E. Nicolas, J.-L. Veyrune, B. Lesourd, and C. Lassauzay, "Nutritional status, dietary intake and oral quality of life in elderly complete denture wearers," Gerodontology, vol. 29, no. 2, pp. e685-e692, 2012.

[33] G. McKenna, P. F. Allen, A. Flynn et al., "Impact of tooth replacement strategies on the nutritional status of partiallydentate elders," Gerodontology, vol. 29, no. 2, pp. e883-e890, 2012.

[34] N. Prakash, N. Kalavathy, J. Sridevi, and K. Premnath, "Nutritional status assessment in complete denture wearers," Gerodontology, vol. 29, no. 3, pp. 224-230, 2012.

[35] A. Sheiham and J. Steele, "Does the condition of the mouth and teeth affect the ability to eat certain foods, nutrient and dietary intake and nutritional status amongst older people?" Public Health Nutrition, vol. 4, no. 3, pp. 797-803, 2001.

[36] E. Nurk, C. A. Drevon, H. Refsum et al., "Cognitive performance among the elderly and dietary fish intake: The Hordaland Health Study", American Journal of Clinical Nutrition, vol. 86, no. 5, pp. 1470-1478, 2007.

[37] B. M. van Gelder, M. Tijhuis, S. Kalmijn, and D. Kromhout, "Fish consumption, n-3 fatty acids, and subsequent 5-y cognitive decline in elderly men: the Zutphen elderly study," American Journal of Clinical Nutrition, vol. 85, no. 4, pp. 11421147, 2007.

[38] J.-M. Kim, R. Stewart, M. Prince et al., "Dental health, nutritional status and recent-onset dementia in a Korean community population," International Journal of Geriatric Psychiatry, vol. 22, no. 9, pp. 850-855, 2007.

[39] D. Zambón, M. Quintana, P. Mata, R. Alonso, J. Benavent, F. Cruz-Sánchez et al., "Higher incidence of mild cognitive impairment in familial hypercholesterolemia," The American Journal of Medicine, vol. 123, no. 3, pp. 267-274, 2010.

[40] K. L. Tucker, N. Qiao, T. Scott, I. Rosenberg, and A. Spiro III, "High homocysteine and low B vitamins predict cognitive decline in aging men: The Veterans Affairs Normative Aging Study," American Journal of Clinical Nutrition, vol. 82, no. 3, pp. 627-635, 2005. 
[41] H. Kim, G. Kim, W. Jang, S. Y. Kim, and N. Chang, "Association between intake of B vitamins and cognitive function in elderly Koreans with cognitive impairment," Nutrition Journal, vol. 13, no. 1, article 118, pp. 1-11, 2014.

[42] G. McNeill, X. Jia, L. J. Whalley et al., "Antioxidant and B vitamin intake in relation to cognitive function in later life in the Lothian Birth Cohort 1936," European Journal of Clinical Nutrition, vol. 65, no. 5, pp. 619-626, 2011.

[43] L. J. Dominguez and M. Barbagallo, "The relevance of nutrition for the concept of cognitive frailty," Current Opinion in Clinical Nutrition \& Metabolic Care, vol. 20, no. 1, pp. 61-68, 2017.

[44] F. Gómez-Pinilla, "Brain foods: the effects of nutrients on brain function," Nature Reviews Neuroscience, vol. 9, no. 7, pp. 568$578,2008$.

[45] F. Gomez-Pinilla and E. Tyagi, "Diet and cognition: Interplay between cell metabolism and neuronal plasticity," Current Opinion in Clinical Nutrition \& Metabolic Care, vol. 16, no. 6, pp. 726-733, 2013.

[46] G. Faraco and C. Iadecola, "Hypertension: A harbinger of stroke and dementia," Hypertension, vol. 62, no. 5, pp. 810-817, 2013.

[47] T. Ninomiya, T. Ohara, Y. Hirakawa et al., "Midlife and late-life blood pressure and dementia in japanese elderly: the hisayama study," Hypertension, vol. 58, no. 1, pp. 22-28, 2011.

[48] S. Köhler, M. A. E. Baars, P. Spauwen, S. Schievink, F. R. J. Verhey, and M. J. P. Van Boxtel, "Temporal evolution of cognitive changes in incident hypertension: Prospective cohort study across the adult age span," Hypertension, vol. 63, no. 2, pp. 245-251, 2014.

[49] A. R. Atti, K. Palmer, S. Volpato, B. Winblad, D. De Ronchi, and L. Fratiglioni, "Late-life body mass index and dementia incidence: Nine-year follow-up data from the Kungsholmen Project," Journal of the American Geriatrics Society, vol. 56, no. 1, pp. 111-116, 2008.

[50] M. Kivipelto, T. Ngandu, L. Fratiglioni et al., "Obesity and vascular risk factors at midlife and the risk of dementia and Alzheimer disease," JAMA Neurology, vol. 62, no. 10, pp. 15561560, 2005.

[51] J. M. Noble, L. N. Borrell, P. N. Papapanou, M. S. V. Elkind, N. Scarmeas, and C. B. Wright, "Periodontitis is associated with cognitive impairment among older adults: analysis of NHANES-III," Journal of Neurology, Neurosurgery \& Psychiatry, vol. 80, no. 11, pp. 1206-1211, 2009.

[52] D. W. Molloy and T. I. M. Standish, "A guide to the standardized Mini-Mental State Examination," International Psychogeriatrics, vol. 9, no. 1, pp. 87-94, 1997.

[53] J. L. Leake, "An Index of Chewing Ability," Journal of Public Health Dentistry, vol. 50, no. 4, pp. 262-267, 1990.

[54] P. Philip, C. Rogers, E. Kruger, and M. Tennant, "Oral hygiene care status of elderly with dementia and in residential aged care facilities," Gerodontology, vol. 29, no. 2, pp. e306-e311, 2012.

[55] X. Chen, J. J. Clark, H. Chen, and S. Naorungroj, "Cognitive impairment, oral self-care function and dental caries severity in community-dwelling older adults," Gerodontology, vol. 32, no. 1, pp. 53-61, 2015.

[56] M. Nakata, "Masticatory function and its effects on general health," International Dental Journal, vol. 48, no. 6, pp. 540-548, 1998.

[57] D. Ekuni, T. Tomofuji, K. Irie et al., "Occlusal disharmony increases amyloid- $\beta$ in the rat hippocampus," NeuroMolecular Medicine, vol. 13, no. 3, pp. 197-203, 2011.
[58] T. Yamamoto and A. Hirayama, "Effects of soft-diet feeding on synaptic density in the hippocampus and parietal cortex of senescence-accelerated mice," Brain Research, vol. 902, no. 2, pp. 255-263, 2001.

[59] T. Muramoto, Y. Takano, and K. Soma, "Time-related changes in periodontal mechanoreceptors in rat molars after the loss of occlusal stimuli," Archives of Histology and Cytology, vol. 63, no. 4, pp. 369-380, 2000.

[60] F. Bunn, A.-M. Burn, C. Goodman et al., "Comorbidity and dementia: A scoping review of the literature," BMC Medicine, vol. 12, no. 1, article no. 192, 2014.

[61] F. Formiga, I. Fort, M. J. Robles et al., "Comorbidity and clinical features in elderly patients with dementia: differences according to dementia severity," The Journal of Nutrition, Health \& Aging, vol. 13, no. 5, pp. 423-427, 2009.

[62] A. Alhebsi, L. D. Pettaway, and L. Waller, "A history of education in the United Arab Emirates and trucial sheikdoms," The Global eLearning Journal, vol. 4, no. 1, 2015. 


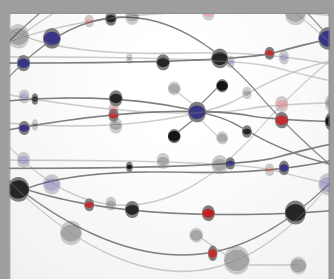

The Scientific World Journal
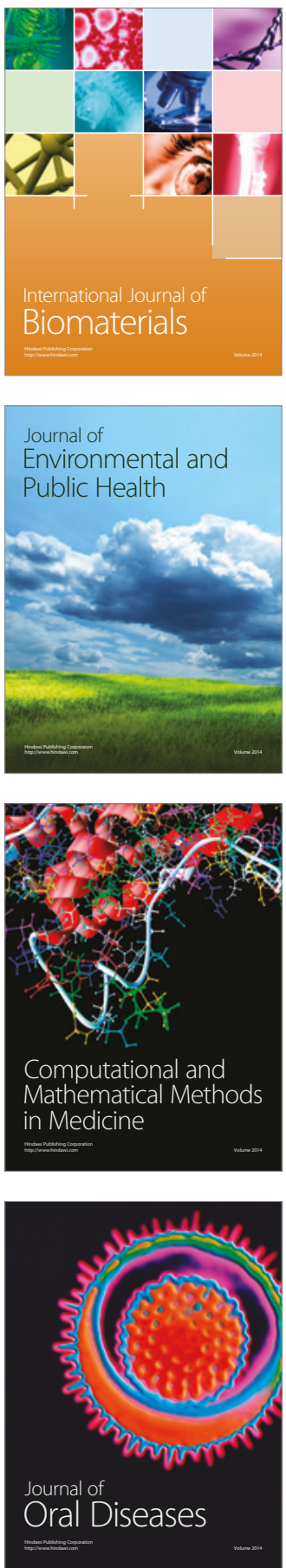
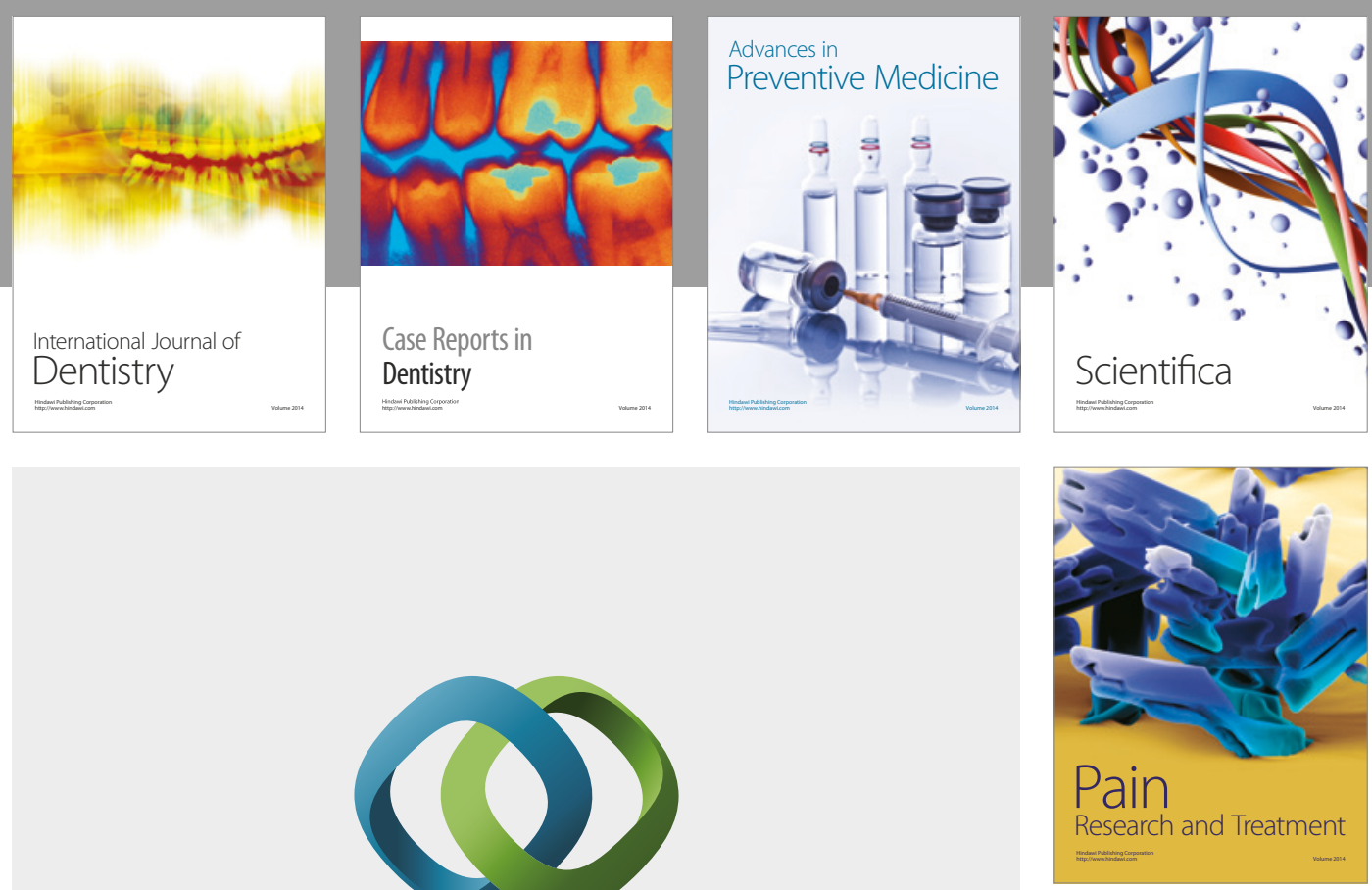

\section{Hindawi}

Submit your manuscripts at

https://www.hindawi.com
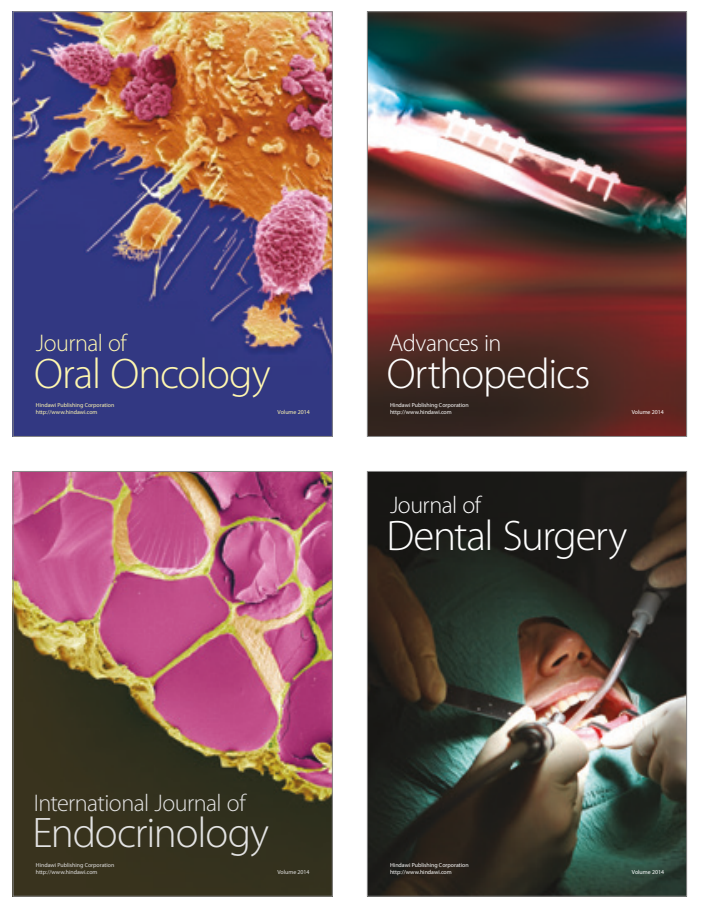
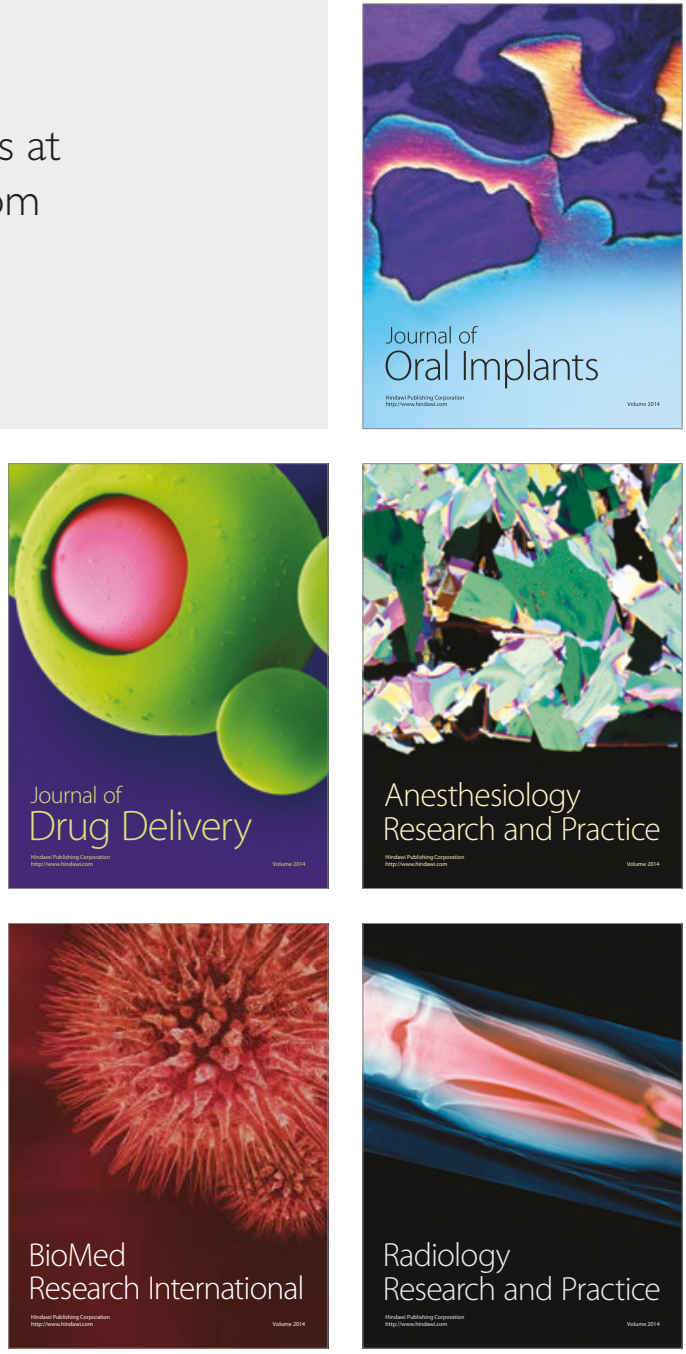